\title{
TWO BEST FRIENDS MIND AND BREATH
}

\section{Dr Nimeshkumar D Chaudhari}

Mind and Prana, so it is said, are one, and thus mind and breath are interdependent. Where there is breath there is thought; without breath the activities of the mind will dry up.

These rather unusual assertions must be investigated further, for they are the core of raja yoga. It is not by accident that the German word Atem (breath), and the Sanskrit term atman (the self) have the same root. In our understanding, to cease breathing means to die. In yoga teaching it may mean death but does not necessarily. Certainly, consciousness in a general sense disappears along with breath, but what really happens after that we do not know. "Unconsciousness" is a meaningless term. Do we really know whether dying and being dead arethe same thing, whether so-called unconsciousness does not encompass innumerable subconscious states? These are just a few problems relating to consciousness. We can become conscious only of events that reflect states, never of states. We are unable to grasp with our conscious mind a state that is not reflected by an event.

We are aware of some of our thought processes, among others those that bring the self into reality: this is "self-consciousness." Everything that I perceive, recognize and judge is a part of my self, for my already existing relationship to the perceived indicates that the image of the object is already part of my store.

Of experience, and that I therefore already have that karma-producing element (the previously-experienced object) "within" me. And my relation to the object is karmically conditioned, as well as karma-producing. It is thus an integral part of my personality.

To the Indian mind it means that we are under an illusion so long as we consider the self as a constant unit that which exists in itself and does not result from the sum total of consciousness factors. Thus the total of what I "know" (even subconsciously) is my self.

The illusion about human personality is fundamental. Where do we get our concept of human personality? As long as we do not get to the root of this question, we fall victim to illusion after illusion.

We watch our conversation partner, recognizing "in him" his personality. We consciously look above all at the eyes, presuming that these organs, designed for seeing, arealso the mirror of the personality. But while we are thus watching the eyes in much the same way as we previously observed the sound of our name, they suddenly do not seem so important any more; in fact, they become insignificant in relationship to the whole personality. The same is true when we observe other single components: mouth, nose, checks, or forehead. Only the sum total of all makes up the personality. We realize that by observing the details we miss the essence. It is as though we were watching the glass rather than the image in the mirror. Then we realize that not even the sum total of all these details gives us the living image of the whole. But what is it?

The human personality is not "in-itsdf," it only becomes, within us. If we look mechanically at the surface we see nothing but the surface. Our inner being alone, not the eye, can see behind the surface. We have no specific name for this subtle inner organ. Heart, intuition, feeling, soul, inner eye--all these are current expressions which are as familiar as they are vague, although they all express the right thing. 


\section{Nimeshkumar Chaudhari / Page 32-39}

So let us look with nonmechanical eyes behind the surface, then we see the image of the object within ourselves inwardly. "Seeing" is only a small fraction of perceiving which essentially means to melt the (outer) image and the (interior) concept into one: simultaneously to see and co feel. And it is the same way with everything that we perceive with our sense organs. In reality it is not only sense perception, for all senses are only tools, organs of communication.

This, our personality-shaping inner world in its sum total, is atman. Yet the thousand little stones that make up a mosaic are, in their multitude, far from being a picture. Decisive is the manner in which they are put together into a pattern. It is this unity alone that creates the complete impression, not analytical observation; it is the inner perception that is based on something higher than the sum total of the individual pieces.

These countless elements of consciousness are united into the living total personality through prana, which has its source in breath. Thus the spirit, the human essence, is born of breath. And so, in a way, we breathe in the world, and breathe it out in the "form" of the personality thus created. The problem that concerns yoga is the creation of a harmonious relationship between the static personality components (the atman, the mosaic picture) and the dynamic personality (the creative artist's mind). In Indian terms, this means the harmonious marriage between static Purusha and dynamic Prakriti (shakti), between the human personality and its inherent forces,

- When the mind it still, united with the atman, and prana flows through the sushumna then [even the extraordinary] amaroli, vayoli and sahojoli can be reached [that is. to voluntarily reverse the flow of semen].

In other words, there is no limit to the extent of accomplishments.

- (15) How can one reach perfection of knowledge [jnana] when the breath is still living [in consciousness' and the mind [as a manifesting force separate from it] has not died? He who can cause prana and mind to become suspended, one through the other, reaches liberation.

- Once he knows the secret, how to find the way to the sushumna and how to induce the air to enter it, he should settle down in a suitable place [and not rest] until [the kundalini has reached] the crown of the head [brahmarandhra].

We already know why this is necessary. The chakras, these activity centers of karma, have been penetrated, and since the yogi's karma has thus been eliminated so that his mind is no longer sullied and led astray by blindness and ignorance, this illuminated mind can now melt with the atman into perfect union. This takes place in the brahmarandhra, in the sahashrara chakra.

- Sun and moon cause day and night. The sushumna [however] swallows time. This is a secret.

- Here is an odd fact: if you observe the flow of breath for a whole day you will observe that you breathe more intensely at times through the right nostril and at other times through the left; now the right nostril seems stopped up and now the left. It seldom occurs that we breathe evenly through both nostrils. There is always a difference, no matter how slight. This is not due to a cold, but to the fact that the supply of breath through the one nostril has a different effect on the prana than that through the other. Breathing through the right nostril furthers extroversion; through the left, introversion. The breathing apparatus regulates itself automatically, so that through the lack of active elements the left nostril closes up slightly from the inside, causing the breath to flow chiefly through the right, and the active side of the body gets the greater supply. Mental fatigue is mostly preceded by a lengthy period of breathing through the left nostril.

One can (and frequently does) even out the imbalance by intensified one-sided pranayama. But the yogi has another method which, though applied externally, has an internal effect: He puts pressure on the side of the body which is overactive by lying on that side with arm strongly pressed to the body. Or he uses a special tool that he carries with him: a short crutch with a cross beam which he clamps into his armpit, while resting the lower end on the ground where he is sitting. After a few minutes the nostril of the side upon which pressure is being exerted will close up, and with this the field of prana changes over to the other side. 


\section{Normally the prana flow automatically changes in a regular rhythm, usually every two hours.}

The reference here to the sun and the moon is not, as previously implied, to the source of nectar and its opposite pole in the area of the diaphragm, but to the ida nadi (moon) and the pingala nadi (sun). "Day" means prana supply to the pingala nadi (right nostril) and "night" prana to the ida nadi (left nostril). The cleansing of the nostrils (neti) which is part of the shatkarma (sixfold cleansing process) is designed to prevent an unnatural clogging that can block the natural breathing rhythm.

If prana is to enter sushumna then there must be neither "day" nor "night"; breath must flow precisely evenly through both nostrils. This in turn presupposes an exact balance of active and passive elements. In short, only he who has achieved complete inner equilibrium can have success in kundalini.

There are 72,000 nadis in this cage [body]. Sushumna is the central nadi which contains the shabhavi shakti. This has the property of bestowing bliss upon the yogi. All others are then useless. --Guide the prana into the sushumna and kindle the gastric fire and awaken the kundalini. Only when prana fiows through the sushumna wilt there be samadhi. All other methods are futile. When breath is suspended then [discursive] thinking also is suspended. He who has power over his mind can also control prana.

The deepest sense of this yoga will be understood only by one who is convinced that from physical process to psychological experience and religious phenomena there is one straight (if usually secret) path, and that none of the three can exist and function by itself. He who is prepared to familiarize himself with what naturally seems to be a strange terminology will find not only confirmation of the most modern knowledge, but the possibility of new insights as well, for the problem of relationship between the inner and outer worlds will always be a topical one as long as the human race exists. The last word on it can never be expected, for each culture, even each phase of individual life presents new perspectives. It is by the great visionary works of antiquity that we are most deeply touched-- we who have become so clever.

Mind and prana are related to each other like milk and water. If the one dries up the other one also dries up. In whatever chakra the prana is concentrated mind becomes fixed, and where the mind is fixed prana is conquered.

The fact that men's cultural levels differ so greatly is not simply a problem of society; nor does it depend on ambition, or even on intelligence. It is really the chakras that cause stratification in culture.

Genius is the product of the highest development potential of that chakra by which it lives. As long as our mind is not nourished by that same chakra we only comprehend the lower levels. At the highest level our understanding is no longer limited. There we need no intellectual hints; we perceive the spirit everywhere, even in silence.

The chakra determines whatever level of development we are on, and this level determines the measure of our consciousness.

Alchemy and magic--or only kindred symbols? Mercury is the symbolic square of the earth, the mulandhara chakra. The alchemical process represents the rising to the second chakra, svadhisthana. He who transcends the three lowest centers attains the fourth chakra, anahata, the vibration domain of the air. "He rises into the air." That is, he ultimately rises above the worldly spheres of earth, water and fire, into higher regions. As long as the spirit is not free from the lower spheres, it is not "held fast."

When mind is held fast, prana is also held fast, as is the bindu in which the sattva element of the body is established.

In the first sloka of Part Four we translated the word bindu as "sense," (that is, the principle of intelligence). However, the word is so ambiguous that this translation is just a stopgap. Bindu may stand for: drop, period, zero, seed, the void. These appear to be quite different concepts, and one asks 


\section{Nimeshkumar Chaudhari / Page 32-39}

how the translator can add a sixth. Here we get a glimpse of the depth of the Sanskrit language, for each of these concepts has enormous significance.

Period (dot), It does not stand like a tombstone at the end of a Sanskrit sentence, but is the sign for vocal vivification. The dot above the consonant (which is always connected with a vowel) changes a dull ka into a rich kam or kang, a ta into tarn or tang, pa into pam, and so on, through all the consonants. It adds vibration to the dull sound. It is especially significant that it raises o from the chest vibration to the $0 \mathrm{~m}$ sound in the head, the higher sphere. Thus it raises the physical sound to the chakra of consciousness, the ajna chakra between the eyebrows, and gives it meaning. In this way, the dot becomes the symbol for "sense."

The zero, Just as the dot is both a "nothing" and the symbol for sense, so is zero. By itself it is a symbol of no-thing. Added to a figure it increases its value tenfold. It gives the figure a value, a value that the figure by itself possesses only potentially. It catalyzes something essential without possessing a tangible value of its own.

The seed, Only when it falls upon fertile ground can it sprout. Like the dot, like the zero. And here the latent value is especially clear.

The void, Here again it is the meaning that makes emptiness purposeful.

Thirty spokes unite around the nave. The void between them makes them useful as a wheel. We shape a pot from day.

Its usefulness depends upon the void that clay surrounds. The house is made of walls, windows and doors. The void between the walls makes it a habitation. We need what is; What-is-not makes it useful.

Now it should be clear why bindu means "sense." The sattva principle in which the "sense" is founded is fulfilled purity in the saint, who is all sattva.

We enter a church and feel the sattva element that governs the lofty sacred room. Something like a shiver of enchantment pene-

trates us. It is bindu that (for a moment) transfigures us. We know that it has to do with the divine, to which this place is dedicated. We know it, but the inner concept of this "divine" is more than the word; it is that which speaks within us, nada. Let us recognize this: not the specific term "the divine" exercises its power, but the "inner something" that vibrates with this concept. Then the concept as such, with its thought content, dissolves (laya), and what remains is the experience of the spirit. This phrase, "experience of the spirit," already contains the duality: prana (experience) and spirit.

So much for our everyday experience. For the yogi approaching samadhi, the process is reversed: he has recognized the meaningful germ, bindu, within himself, and knows that the divine vibrations in him were merely released by the sattva element in the outside stimulation.

Therefore, like the ancient master mystics, he turns inward and finds liberation in detachment from the releasing element. For liberation means "nothing but" freedom from exterior influences.

The water. Out of these three grows the tree that fulfills all wishes. --Through assiduous practice of concentration on nada, all sins are destroyed, and mind and prana become dissolved in absolute consciousness During samadhi the body becomes like a log. The sound of the conch and of the big drum pass by his ear .

- The yogi is free from all states, from all thoughts. He is like one dead. And yet he is master of death, of his fate, and his enemies. His senses have died away; he nows not himself or others. He is one who it liberated in this lifetime, when his mind is neither awake nor asleep, and when he is free from remembering and forgetting. He does not live, and yet he is not dead. - - He is impervious to heat and cold, to pain and bliss, to honor and insult. --He seems to be sleeping, and yet he is awake. inhalation and exhalation have subsided.

--Weapons cannot harm him, no human power can overcome him. He is beyond curses and charms.

--But as long as prana does not enter the sushumna and reach its highest goal at the crown of the head, as long as the absolute is not manifested in samadhi, as long as the I does not become one with the it, so long are those who talk about dissolution in Brahman mere babblers and prevaricators. 


\section{A Mindful Breathing Script}

Start by settling into a comfortable position and allow your eyes to close or keep them open with a softened gaze. Begin by taking several long slow deep breaths breathing in fully and exhaling fully. Breathe in through your nose and out through your nose or mouth. Allow your breath to find its own natural rhythm. Bring your full attention to noticing each in-breath as it enters your nostrils, travels down to your lungs and causes your belly to expand. And notice each out-breath as your belly contracts and air moves up through the lungs back up through the nostrils or mouth. Invite your full attention to flow with your breath.

Notice how the inhale is different from the exhale. You may experience the air as cool as it enters your nose and warm as you exhale. As you turn more deeply inward, begin to let go of noises around you. If you are distracted by sounds in the room, simply notice them and then bring your intention back to your breath. Simply breathe as you breathe, not striving to change anything about your breath. Don't try to control your breath in any way. Observe and accept your experience in this moment without judgment, paying attention to each inhale and exhale.

If your mind wanders to thoughts, plans or problems, simply notice your mind wandering. Watch the thought as it enters your awareness as neutrally as possible. Then practice letting go of the thought as if it were a leaf floating down a stream. In your mind, place each thought that arises on a leaf and watch as it floats out of sight down the stream. Then bring your attention back to your breath. Your breath is an anchor you can return to over and over again when you become distracted by thoughts.

Notice when your mind has wandered. Observe the types of thoughts that hook or distract you. Noticing is the richest part of learning. With this knowledge you can strengthen your ability to detach from thoughts and mindfully focus your awareness back on the qualities of your breath. Practice coming home to the breath with your full attention. Watching the gentle rise of your stomach on the in-breath and the relaxing, letting go on the out-breath. Allow yourself to be completely with your breath as it flows in and out.

You might become distracted by pain or discomfort in the body or twitching or itching sensations that draw your attention away from the breath. You may also notice feelings arising, perhaps sadness or happiness, frustration or contentment. Acknowledge whatever comes up including thoughts or stories about your experience. Simply notice where your mind went without judging it, pushing it away, clinging to it or wishing it were different and simply refocus your mind and guide your attention back to your breath.

Breathe in and breathe out. Follow the air all the way in and all the way out. Mindfully be present moment by moment with your breath. If your mind wanders away from your breath, just notice without judging it - be it a thought, emotion, or sensation that hooks your attention and gently guide your awareness back to your breathing.

As this practice comes to an end, slowly allow your attention to expand and notice your entire body and then beyond your body to the room you are in. When you're ready, open your eyes and come back fully alert and awake. The breath is always with you as a refocusing tool to bring you back to the present moment. Set your intention to use this practice throughout your day to help cultivate and strengthen attention.

\section{The Connection between Breath and Mind}

The moment a child is born and it takes the first breath, the saga of mind-breath friendship begins, and all through life it maintains the bonds of interdependence. However, in this materialistic world, the five senses take over the reigns of the mind, clouding it with unending desires and attachments, making one ride, endlessly, the waves of pleasure and pain, joy and sorrow, health and disease and many such opposing dualities.

Getting signals from the five senses, the mind naturally has the upper hand over the breath, as all thoughts arise in the mind. Thus, the pace and quality of breath going in and out of the body is dependent on the state of the sense-driven mind at any given point of time. A disturbed, ruffled mind laden with negative thoughts may, for example, manifest outwardly in the form of anger, which in 
turn, makes the heart beat faster and therefore, the breath is short and fast. Too much labored breath is experienced when, again, the mind is not calm but anxious and over-burdened with racing thoughts. Restlessness of the mind is a common experience for most people and, undoubtedly, as the breath follows the mind, afflictions of the body related to poor oxygen supply; heart problems and depression, among several other illnesses, are also common. On the other hand, it is also a common experience that, when we think positively, we feel calmer and our breath is correspondingly slow and deep.

Does this mean that, for most of us, the uncontrolled mind dictates the pace of breath? Yes. Sadly, it is so. Paramhansa Yogananda said that "Breath is the cord that ties the soul to the body and breathlessness is the way to God." In this state of breathlessness, the mind is completely still and relaxed, which is the altar of God. But as the mind vacillates due to a sense-driven outward flow of energy, it cannot perceive the all-pervading God consciousness.

Now, how to still the ever restless mind? The solution lies in tricking the mind into entering a state of stillness by conscious control of the in-going and out-going breath, by pranayama. That is why Yogananda said that, to know God, you must practice pranayama. This means that instead of breath following the mind, the mind could be made to follow the breath if conscious effort is made on our part to control the it - the only trick to control the monkey mind!

\section{Techniques for Spiritual Development with the Breath}

Kriya yoga meditation is the highest pranayama technique. The outcome is wondrous. By its continual practice, the breath slows down and, in deeper states of meditation, breathlessness occurs. As the mind follows the breath, like a faithful friend, it now becomes absolutely still and merges with Divine consciousness. A beautiful story in Bhagavad Gita illustrates this point. One day, as the Gopis were visiting Lord Krishna, they decided to take some offerings for Him. Now, what could they offer the Lord when He already had everything? They began to contemplate and finally decided to offer their restless minds, which the Lord did not have. Thus offering their restless minds to Him, through breath control in meditation, they achieved absolute stillness and, in return, what the Lord gave them was the experience of His soul-satisfying omnipresence! In this way we experience one or more of His eight attributes: light, sound, joy, love, peace, calmness, wisdom and power, as the outcome of deep meditation.

What most of us have experienced is that even taking a few deep, long breaths at times of emotional upsurge, when the mind is too restless, can instantly calm it. The Hong Sau technique given by Yoganandaji is a simple, yet powerful way to bring to rest the wandering mind by centering its energy in one direction. Yoganandaji said, "By the practice of the Hong Sau technique you develop such power of concentration that when you attempt to draw your mind within, it obeys you." As we sit in meditation posture, mentally chanting the mantra 'Hong' with every inhalation and 'Sau' with the exhalation, the breath becomes slower and slower, with increasing length of pauses between two cycles. With this calm breath and heart, the bodily sensations disappear and the mind's energy is directed upwards as the inner gaze, at this moment, is focused at the point between the eyebrowsthe Kutastha Chaitanya or the Christ center, which is the seat of Higher consciousness. Here, the mind experiences the presence of God which is commonly perceived as peace.

\section{The Battle of Delusion - The Need of Self-Effort and Devotion}

The battle is, therefore, between the satanic force of delusion that pulls the mind in the sensedriven materialistic world and the power of our self-effort to pull back the restless mind inward, directing its energy into the spine. If delusion succeeds in driving our mind into worldly activities, the breath then follows the restless mind. The reverse happens if our self-effort for doing meditation or pranayama is strong enough to thwart the worldly desires in favor of controlling the breath: miraculously, the mind is calmed. In other words, whether making a determined effort to tame the mind through breath control; or allowing the ever-restless mind, engrossed in material world, to play havoc with the flow of our breath, is purely our choice! Mostly, people realize the folly of riding the waves of delusion only after experiencing tremendous emotional turmoil and unbearable suffering. 


\section{Nimeshkumar Chaudhari / Page 32-39}

This sufferance is because the breath follows such uncontrolled mind, full of desires and attachments, while in a spiritually inclined person, the opposite becomes true and the mind is tamed by breath control.

Self-discipline is indeed pertinent to disciplining the mind. Patanjali's eight fold path of yoga is a structured, step-by-step way to free the mind from restless thoughts and the constant distractions of sensations. For this, there are first five attitudes to avoid called 'Yamas' (Non-harmfulness, Nondeceit, Non-covetousness, Non-sensuality/Continence, Non-attachment); second, the five attitudes to cultivate, called 'Niyamas' (Cleanliness/Purity, Contentment, Austerity, Self-study/Introspection, Worship/Devotion to God); the next is 'Asana', the ability to have a relaxed meditation pose with the spine straight; the fourth stage is 'Pranayama' or control of breath and energy; followed by the fifth state of 'Pratyahara' where the interiorization of mind occurs; then comes 'Dharana' or calm inner awareness or concentration, one-pointed focus; leading to 'Dhyana' or meditation or absorption, and finally reaching the eighth state that is 'Samadhi' or the highest awareness where the soul becomes one with Spirit.

Devoting one's life to the Divine search with steadfastness is important, as a brief meditation done now and then without singularity of purpose to find God keeps the breath following the restless mind. We do not know for how many incarnations our breath has been ceaselessly following the mind, but solace comes from the words of Swami Sri Yukteshwarji who said that "Everything in future will improve if we make the spiritual effort now." This reassurance is for all spiritual aspirants to make concerted effort to do pranayamaregularly so that the restless mind reverses its direction inward and learns to follow the breath, for in it lies the victory of re-establishing in us the joy of soul consciousness, the happiness that we are all searching for!

Our self-effort is, however, not enough to push the tremendous force of delusion that pulls the mind towards the senses again and again. The essential key, coupled with our self-effort to control the breath through pranayama, is to draw the Guru's grace through attunement by our heart's devotion and love for the Guru, for this combination alone can help us remain unshaken amidst worldly pressures as we then remain even-minded, come what may. That is the state we are all striving to achieve. Ironically, what a tug of war as to who follows whom between, breath and mind, the two best friends!

\section{Conclusions:}

I can verily experience the enigmatic engagement between the 2 best friends - what a battle in the subtlest degree! The roaring, speedy mind and the poised, dynamic, powerful breath.

Your mind and your breath are two great friends, inseparable friends, they work together. Therefore when you train your breath, your mind is being trained, for they live together, they are very close friends. To bring the mind under your conscious control means to train your breath which you can easily do. You can easily control that mind which is called roving mind, and once you are able to do that, you'll have faith in your practices, you'll have confidence and then you'll go beyond. For that, a little bit more effort is required, but nothing is impossible.

The ultradian rhythm associated with nostril breathing is well known to the Yogic tradition. Pressure applied to some parts of the body is known to result in unilateral breathing and thus aid in achieving higher states of consciousness. The results related to nostril breathing and the autonomic balance is very important and very recent to be applied effectively in therapy. Brain, cardiac and respiratory functions are coupled strongly through the autonomic nervous system and manipulation of breath could change the activity in these organs. Thus the role of Prana, if it may be called, in maintaining health is at last being investigated. Pranayama is a simple technique and could turn out to be a profound method for the management of psychosomatic disorders.

\section{References:}

1. Swami Vivekananda, Raja Yoga Advaita Ashram, Calcutta, p. 232 (1947).

2. Swami Digambarji and Pundit Kopkaje (Ed), Hatapradipika of Svatmarama Kaivalyadhama SMYM, Lonavala, p. 52 - 59 (1970). 
3. B. K. S. Iyengar, Light on Pranayama Cross road, N. Y., p. 14 (1989). Sir John Woodroffe The serpent power, being the Satcakra Nirupana Ganesh and Co., Madras, p. 212 - 213.

4. Swami Vishnudevanand: The Complete Illustrated book of Yoga. The Julian Press, N. Y., p. 24 (1960)

5. Yogi ramacharaka, The hindu-yogi Science of Breath, London L.N. Fowler \& Co. Ltd.29 Ludgate Hill, London E.C.4, (2003)

6. www.breatheology.com

\section{Dr Nimeshkumar D Chaudhari \\ Assistant Professor \\ Gujarat vidyapith, Ahmedabad}

Faculty of Physical Education \& Sports Science,

At. Sadra, Dist. Gandhinagr. St. Gujarat. India

Pin No. 382320

M:- 09426854903

Email:- chaudharinimesh@gmail.com 